\title{
Magnesium Modifies the Structural Features of Enzymatically Mineralized Collagen Gels Affecting the Retraction Capabilities of Human Dermal Fibroblasts Embedded within This 3D System
}

\author{
Federica Boraldi ${ }^{1}$, Angelica Bartolomeo ${ }^{1}$, Giulia Annovi ${ }^{1}$, Romain Debret ${ }^{2}$ and \\ Daniela Quaglino ${ }^{1, *}$ \\ 1 Department of Life Sciences, University of Modena and Reggio Emilia, Via Campi 287, Modena 41125, Italy; \\ federica.boraldi@unimore.it (F.B.); angelica.bartolomeo@unimore.it (A.B.); annovigiulia@gmail.com (G.A.) \\ 2 Laboratory of Tissue Biology and Therapeutic Engineering (LBTI), UMR5305 CNRS/UCBL, Lyon 69366, \\ France; romain.debret@ibcp.fr \\ * Correspondence: daniela.quaglino@unimore.it; Tel.: +39-059-2055418
}

Academic Editor: Arne Berner

Received: 14 May 2016; Accepted: 8 June 2016; Published: 15 June 2016

\begin{abstract}
Mineralized collagen gels have been developed as in vitro models to better understand the mechanisms regulating the calcification process and the behavior of a variety of cell types. The vast majority of data are related to stem cells and to osteoblast-like cells, whereas little information is available for dermal fibroblasts, although these cells have been associated with ectopic calcification and consequently to a number of pathological conditions. Therefore, we developed and characterized an enzymatically mineralized collagen gel in which fibroblasts were encapsulated within the 3D structure. $\mathrm{MgCl}_{2}$ was also added during gel polymerization, given its role as (i) modulator of ectopic calcification; (ii) component of biomaterials used for bone replacement; and (iii) constituent of pathological mineral deposits. Results demonstrate that, in a short time, an enzymatically mineralized collagen gel can be prepared in which mineral deposits and viable cells are homogeneously distributed. $\mathrm{MgCl}_{2}$ is present in mineral deposits and significantly affects collagen fibril assembly and organization. Consequently, cell shape and the ability of fibroblasts to retract collagen gels were modified. The development of three-dimensional (3D) mineralized collagen matrices with both different structural features and mineral composition together with the use of fibroblasts, as a prototype of soft connective tissue mesenchymal cells, may pave new ways for the study of ectopic calcification.
\end{abstract}

Keywords: collagen type I; alkaline phosphatase; fibroblast; three dimensional gel; morphology; mineralization

\section{Introduction}

Formation of hard connective tissue, such as dentin, bone and cementum, involves calcium phosphate deposition within a collagen matrix. Apparently, similar mechanisms may take place also in the aberrant calcification of soft connective tissues; nevertheless, regulatory mechanisms, especially in pathologic conditions, are still elusive.

Therefore, exploiting strategies capable of regulating mineral deposition demands a better understanding of cell behavior in a calcified context and requires the development of simple and reproducible models. Due to the complexity of in vivo biomineralization, different in vitro models are frequently applied, most of them providing pro-mineralizing factors' supplementation into the culture medium. 
Despite the use of a variety of natural macromolecules and/or synthetic polymers as organic matrices for hydroxyapatite mineralization, collagen type I is the most recurrent embedding substrate for cell encapsulation due to its biocompatibility and similarity to native extracellular matrix [1,2]. Moreover, mineralized collagen gels, mimicking bone composition, have been extensively studied for bone tissue engineering applications [3,4]. It is well known that collagen per se does not induce mineral formation, requiring the presence of ions/salts [5], of non-collagenous proteins [6] and/or of amorphous calcium phosphate [7]. Nevertheless, an appropriate collagen structure is necessary to guide crystal growth and organization [5], allowing proper collagen-mineral interactions, infiltration of calcium and phosphate within collagen fibrils, as well as hydroxyapatite nucleation [8-10]. Collagen gel mineralization has been either obtained by incorporating hydroxyapatite $[11,12]$, by seeding cells cultured for several days in the presence of pro-osteogenic supplements as $\beta$-glycerophosphate and ascorbic acid [13-15], or by preparing collagen/calcium phosphate multilayers, where mineralization is the result of enzymatic reactions [16] and cells are only spread on the matrix surface. Interestingly, stem cells (i.e., dental pulp stem cells, bone marrow mesenchymal stem cells or adipose stem cells) as well as osteoblasts or smooth muscle cells have been widely investigated, whereas other cell types (i.e., fibroblasts) have captured only little attention, even though they regulate connective tissue biosynthesis and organization and are associated with ectopic calcification, and consequently to a large number of pathologic conditions [17].

The aim of this study was to produce and characterize enzymatically mineralized collagen gels in which cells (human dermal fibroblasts-HDF) were embedded within the three-dimensional (3D) structure.

To achieve this goal, calcium salts $\left(\mathrm{CaCl}_{2}\right)$ and $\beta$-glycerophosphate $(\beta-\mathrm{GP})$, as a source of phosphate, were mixed into the collagen solution in the presence of alkaline phosphatase (ALP), the enzyme that promotes phosphate $(\mathrm{P})$ cleavage from organic phosphate-containing substrates, thus releasing $\mathrm{P}$ capable of reacting with calcium ions to form apatitic deposits. Human dermal fibroblasts were added and mixed with the collagen solution before polymerization (Figure 1). Since collagen polymerization is sensitive to a number of variables such as collagen concentration, $\mathrm{pH}$, temperature or presence of other matrix components (i.e., glycosaminoglycans) [18-21], all experimental conditions were accurately controlled. In the present study, $\mathrm{MgCl}_{2}$ was also added to the collagen solution (Figure 1) since it has been suggested that magnesium: (i) interferes with mineral deposition possibly preventing ectopic calcification [22]; (ii) can be a modifier of collagen assembly [23]; and (iii) is present in calcified nodules in clinical contexts $[24,25]$. 


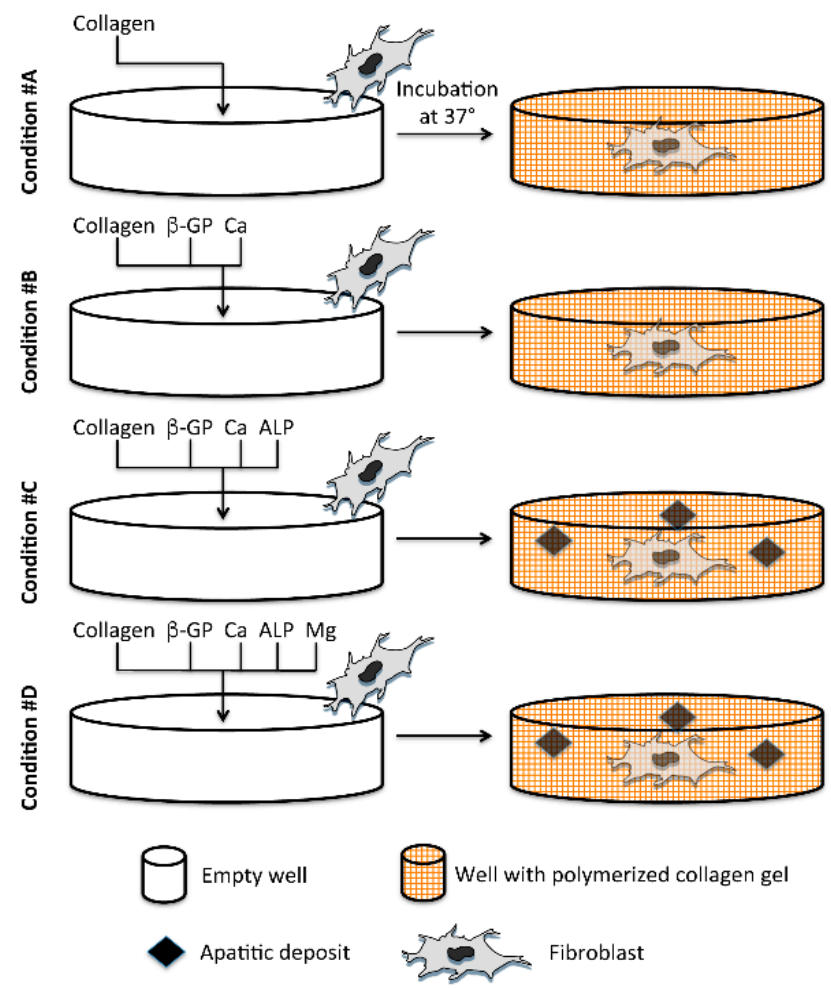

Figure 1. Experimental protocol for collagen gel preparation. Condition \#A is represented by a standard collagen gel and, in sequence, the following components are added: $\beta$-glycerophosphate ( $\beta$-GP) and $\mathrm{CaCl}_{2}$ (Ca) (condition \#B), Alkaline Phosphatase (ALP) (condition \#C) and $\mathrm{MgCl}_{2}(\mathrm{Mg})$ (condition \#D). Presence of ALP in \#C and \#D promotes the cleavage of $\beta$-GP to release phosphate that can react with calcium ions to form apatitic deposits. In all experimental conditions, fibroblasts are added before collagen gel polymerization.

\section{Results}

\subsection{Light and Scanning Electron Microscopy Reveal a Different Structure of Collagen Gels}

Sections of paraffin embedded collagen gels were stained with Anilin blue and observed by light microscopy (Figure 2).

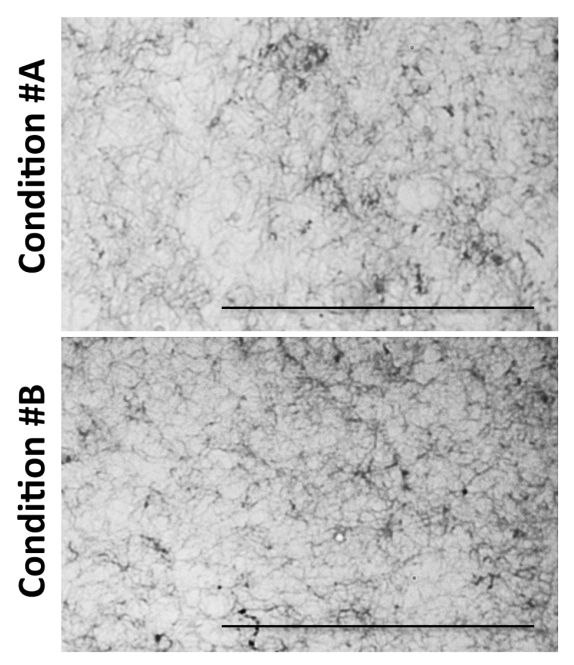

Figure 2. Cont. 


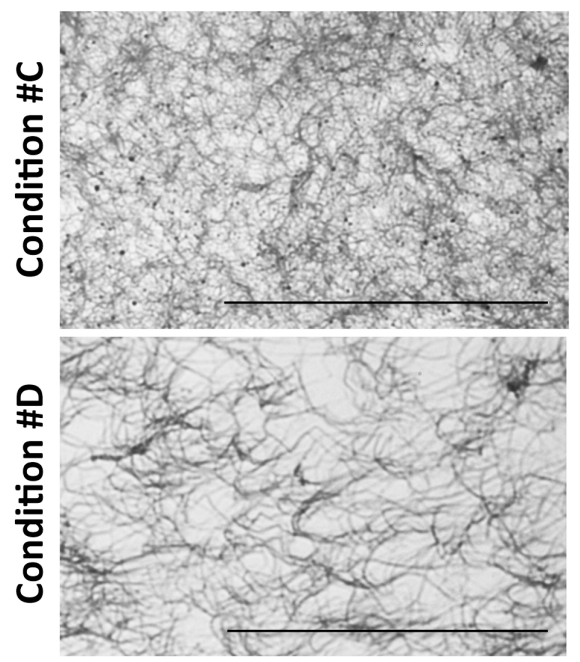

Figure 2. Light microscopy of collagen gels. The fibrillar organization of collagen gels is visualized by light microscopy after Anilin blue staining. Images correspond to the four experimental conditions as in Figure 1. Bar: $100 \mu \mathrm{m}$.

In particular, in conditions $\# \mathrm{~A}$ and $\# \mathrm{~B}$, collagen fibrils were very similar in size and organization, forming a loose 3D structure. In condition $\# \mathrm{C}$, fibrils appeared to be organized in a more compact and intricate network, whereas a completely different 3D organization was noted in condition \#D, where $\mathrm{MgCl}_{2}$ was added. Magnesium chloride was added at concentrations below $100 \mathrm{mM}$ because higher amounts enhance collagen solubility [26]. Surprisingly, fibrils were thicker in diameter, providing a porous structure with larger empty areas between fibrils.

To better visualize the characteristics of collagen gels, samples in the four different experimental conditions were also observed by Scanning Electron Microscopy (SEM) (Figure 3).

\section{- FBS}

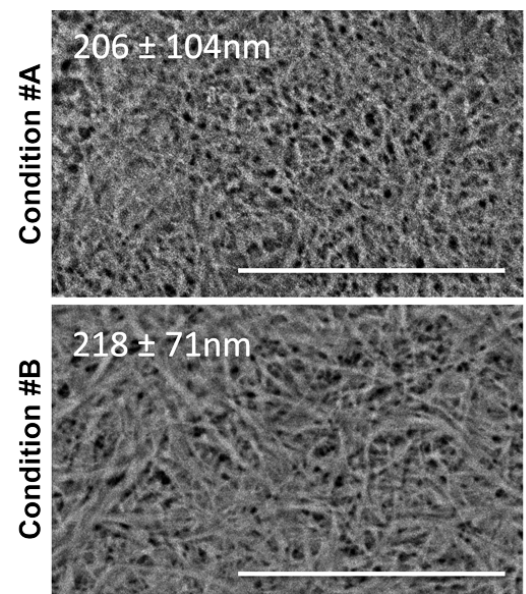

+FBS

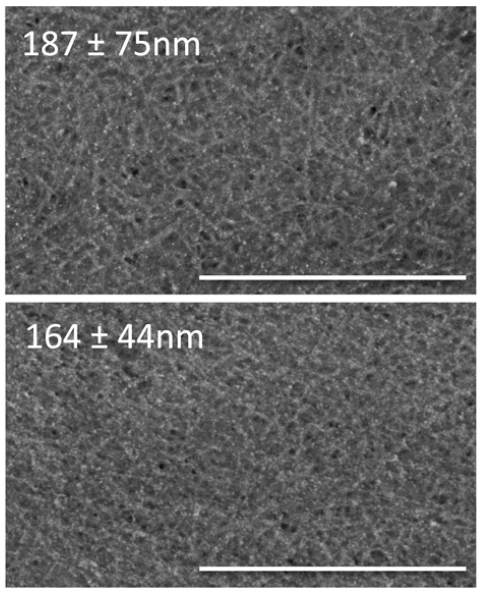

Figure 3. Cont. 

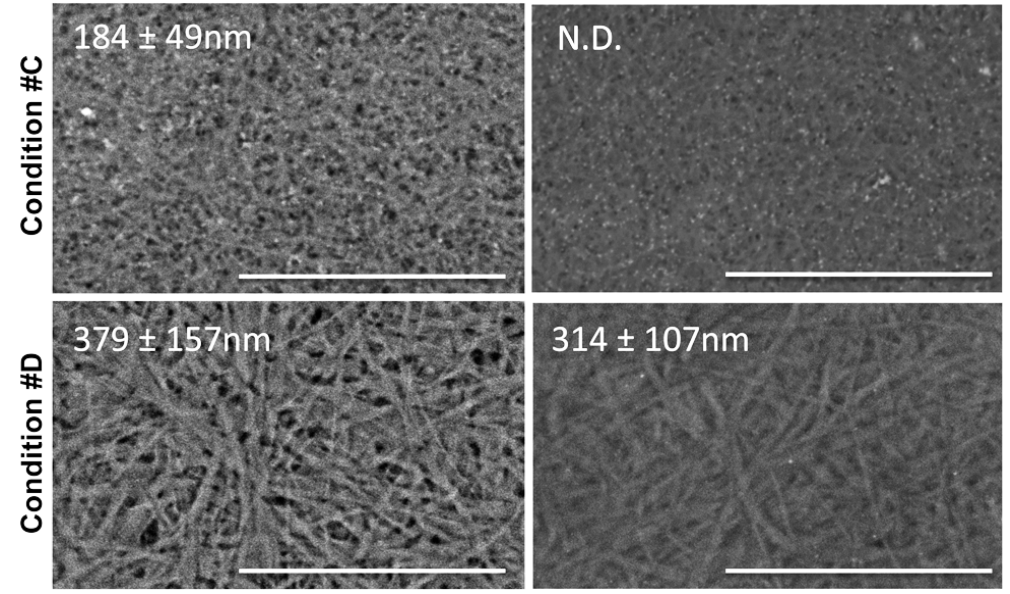

Figure 3. Scanning electron microscopy of collagen gels. Collagen gel organization, in the absence/presence of foetal bovin serum (FBS), is investigated by scanning electron microscopy (SEM). Images correspond to the four experimental conditions as in Figure 1. Values represent the mean diameter of collagen fibrils \pm SD. N.D. not determined. Bar: $10 \mu \mathrm{m}$.

Moreover, since collagen gels represent suitable 3D substrates to be populated by cells that require serum factors' supplementation for their survival and adhesion, morphological observations were performed after placing the gels in standard medium (DMEM) in the absence/presence of FBS (Figure 3).

In the absence of FBS, the structural organization of collagen gels and fibrils' diameters were very similar in conditions \#A and \#B (206 \pm 104 and $218 \pm 71 \mathrm{~nm}$, respectively). For condition \#C, the mean diameter was not significantly different from previous conditions (184 $\pm 49 \mathrm{~nm}$ ), but fibrils appeared more densely packed. In contrast, in condition $\# \mathrm{D}$, there were striking differences in the morphology of the fibrils whose diameter was significantly larger $(379 \pm 157 \mathrm{~nm} ; p<0.001$ condition \#D vs. other conditions) (Figure 3, panel left).

Interestingly, the presence of FBS, added to the medium after gel polymerization, caused an apparently denser matrix, possibly due to serum proteins interacting with collagen fibrils and remaining embedded within the 3D structure; however, diameters of collagen fibrils were not significantly different from those measured in the absence of FBS. It should be noted that, in condition \#C, the presence of FBS rendered gels as murky networks, preventing clear discrimination of collagen fibrils (Figure 3, panel right). The addition of $\mathrm{Mg}$ significantly increased the mean diameter of collagen fibrils ( $314 \pm 107 \mathrm{~nm}, p<0.001$ condition \#D vs. other conditions).

Observations by scanning transmission electron microscopy revealed that $\mathrm{MgCl}_{2}$ supplementation favored the aggregation of collagen fibrils that appeared adjacent one to the other or laterally fused (Figure S1).

\subsection{Mineral Deposition in Collagen Gels Requires ALP Activity}

Mineral deposition was evaluated on collagen gel sections stained with the von Kossa method and observed by light microscopy (Figure 4). 
LM
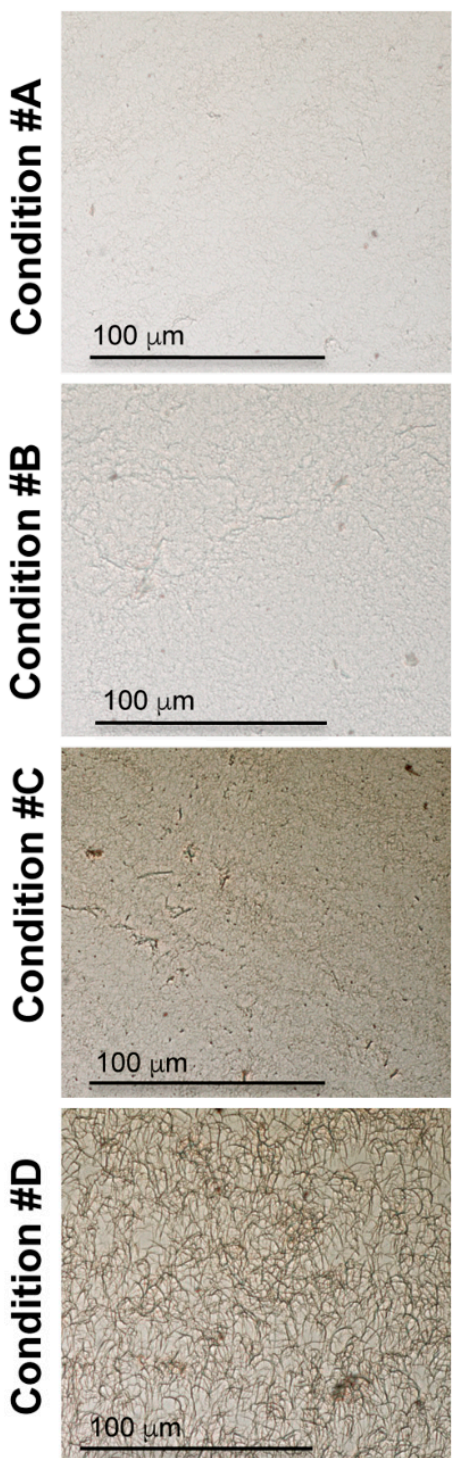

SEM
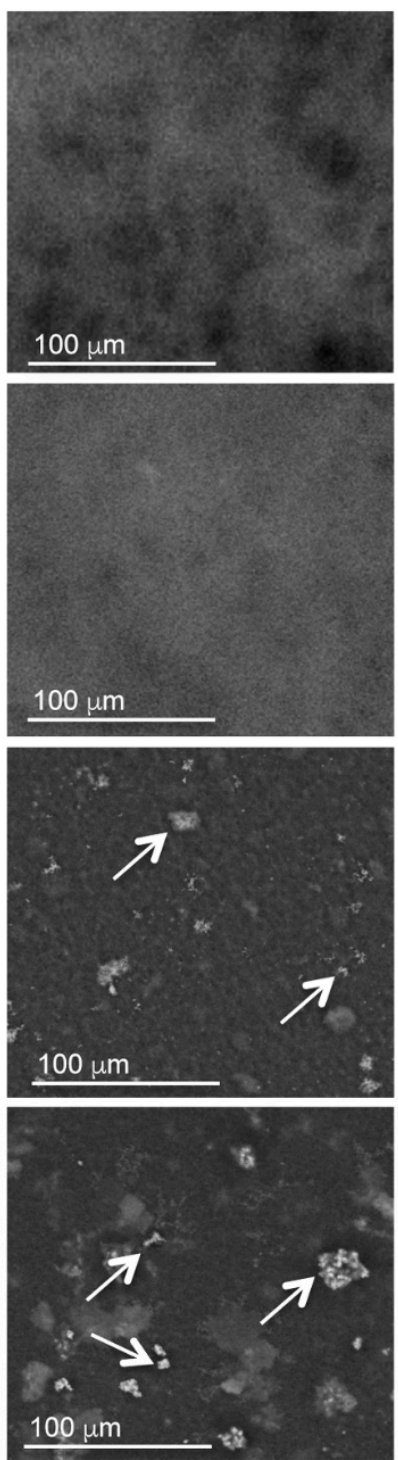

\section{EDS}
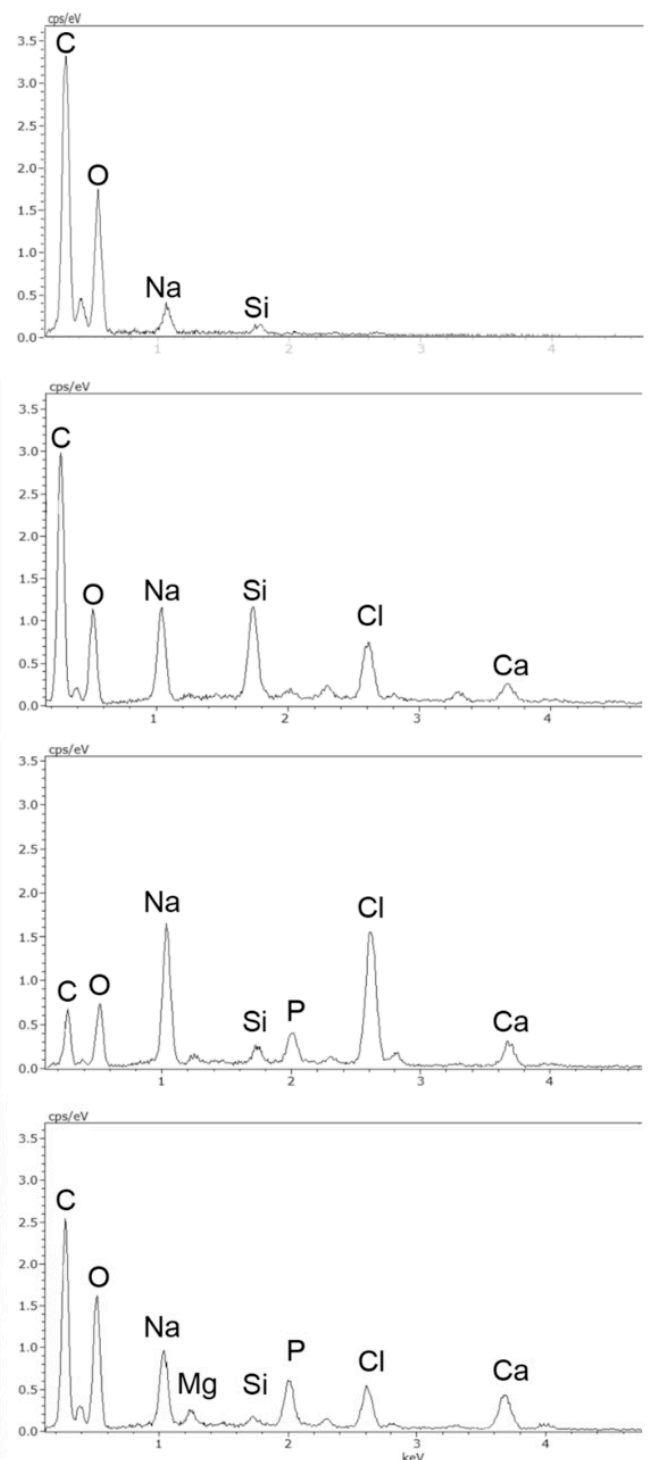

Figure 4. Structural characterization of mineral deposits after $24 \mathrm{~h}$ after gel polymerization. The presence of mineral deposits is visualized by Light Microscopy (LM) after von Kossa staining (brown). Shape and composition of mineral deposits is shown by SEM and Energy-Dispersive Spectroscopy (EDS) spectra. White arrows indicate apatitic deposits.

Twenty-four hours after gel polymerization, paraffin sections from gels prepared in conditions \#A and \#B were devoid of the typical brown staining associated with phosphate deposits, whereas collagen gels containing exogenously added ALP (conditions \#C and \#D) were both positive, confirming that $\mathrm{P}$ was actually cleaved by ALP from P-containing substrates (i.e., $\beta$-glycerophosphate) becoming available to form complexes with calcium.

To confirm the presence of mineral deposits into collagen gels, samples were analyzed by SEM associated with a detector for microanalysis. Distribution of mineral deposits and the corresponding EDS spectra are shown in Figure 4. Gels in conditions \#A and \#B were devoid of mineral deposits. In condition \#A, EDS spectra highlighted the presence of organic matrix components $(\mathrm{C}$ and $\mathrm{O})$ and of $\mathrm{Na}$ derived from the preparing solution, whereas in condition $\# \mathrm{~B}$, we also found $\mathrm{Ca}$ and $\mathrm{Cl}$, consistently with the addition of $\mathrm{CaCl}_{2}$. In both samples the peak of $\mathrm{P}$ was absent. In conditions \#C and \#D, globular deposits were present within the gel, their distribution being rather homogeneous. In addition to the 
elements already described, EDS analysis revealed that the peak of $\mathrm{P}$, as a result of ALP activity, was specifically detected on mineral deposits. It should be noted that in condition \#D, the presence of $\mathrm{Mg}$ was prevalent in the globular structures. Although this approach did not allow for defining the characteristics related to the apatitic nature of mineral deposits, data indicate that $\mathrm{Mg}$ was present in these structures. Finally, since glass slides were used to immobilize collagen gel during analyses, all samples showed a peak corresponding to $\mathrm{Si}$.

\subsection{Homogeneous Distribution but Different Morphology of HDF within Collagen Gels}

The morphology and the distribution of HDF on the surface of collagen gels were assessed by SEM on fixed collagen gels. In all conditions, cells appeared homogeneously distributed; however, in conditions \#A, \#B and \#C, HDF exhibited an elongated shape with extended cytoplasmic protrusions, whereas in condition \#D, the cellular body was more globular with thin branches of various lengths (Figure 5). These results were confirmed by light microscopy on cross-sections of collagen gels embedded in paraffin.

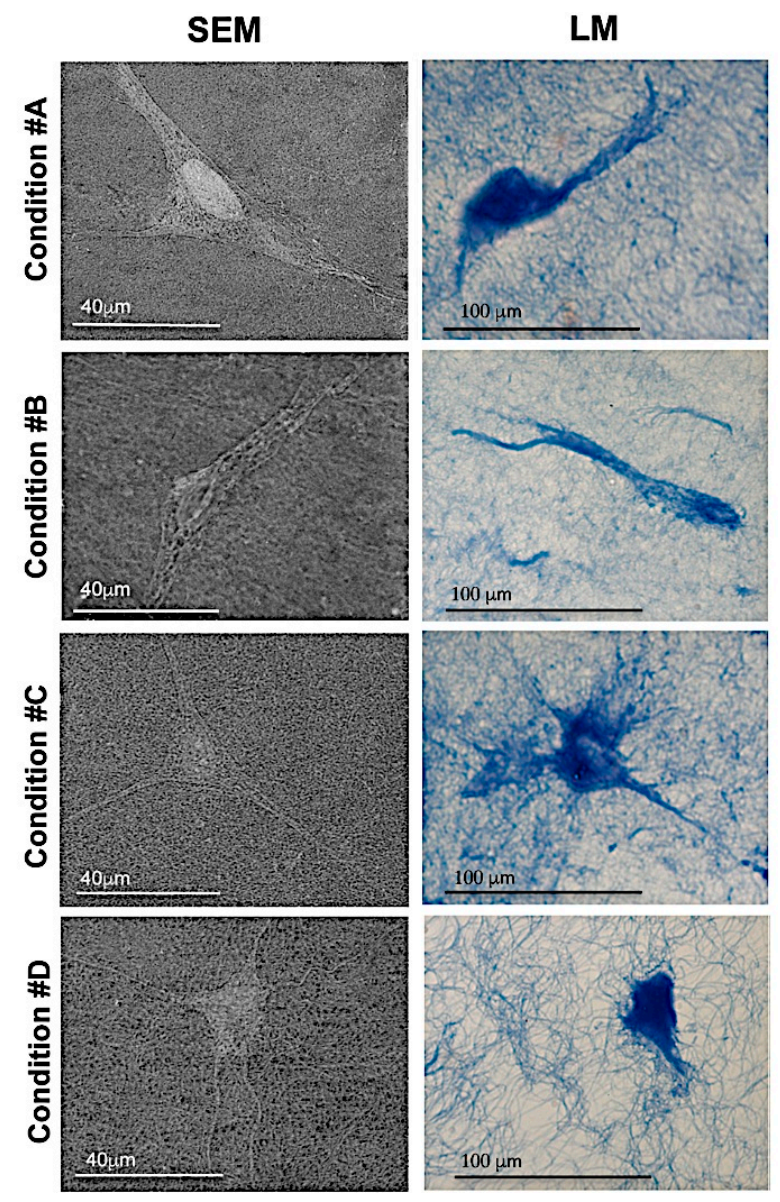

Figure 5. Morphology of fibroblasts embedded within collagen gels. Experimental conditions are those illustrated in Figure 1. Cells are observed by SEM and LM. In condition \#D cells have a less elongated shape.

\subsection{Enzymatically Mineralized Collagen Gel Is Cytocompatible}

Calcein-acetoxymethyl (AM) provides a simple, rapid and accurate method to measure cell viability [16]. Live/dead fluorescence microscopy of HDF embedded within collagen gels is shown in Figure 6. Viable cells, stained green, are visible in all conditions after $48 \mathrm{~h}$ in culture. As a general observation, there is not a great difference between gels with or without ALP, in the presence or 
absence of mineral deposits and in the presence or absence of magnesium. Only a few dead cells $\left(1 \pm 1 / \mathrm{cm}^{2}\right)$, stained by propidium iodide [27], can be seen in all samples (Figure 6). After 24 and $48 \mathrm{~h}$ of gel polymerization, the number of viable cells was quantified by Image J software (open source Java image processing program) (Figure 7). No significant differences were noted over time and among the different experimental conditions. Therefore, the presence of different compounds utilized to develop collagen gels, and the presence of apatitic deposits, do not have cytotoxic effects.

Because collagen gels are characterized by a different structure and by the absence/presence of mineral deposits, the ability of HDF to retract the gels has been evaluated.

As expected, in the absence of serum factors, HDF were not able to contract the gel in any condition, further confirming that serum components are necessary for retraction. In the presence of serum, after $3 \mathrm{~h}$ and $6 \mathrm{~h}$ in culture, collagen gel diameters did not change significantly compared to the initial phase of the experiments. At $24 \mathrm{~h}$ and $48 \mathrm{~h}$ in culture, reduction of gel diameters varied depending on the experimental condition. In particular, at $48 \mathrm{~h}$, collagen gels without mineral deposits $(\# \mathrm{~A} ; \# \mathrm{~B})$ were retracted approximately $25 \%$ of their original diameter. A reduction of $6 \%$ to $35 \%$ of the original gel size was observed for conditions \#C and \#D, respectively ( $p<0.05$ condition \#A or \#B vs. condition \#C and \#D; $p<0.01$ condition \#D vs. condition \#C) (Figure 8).

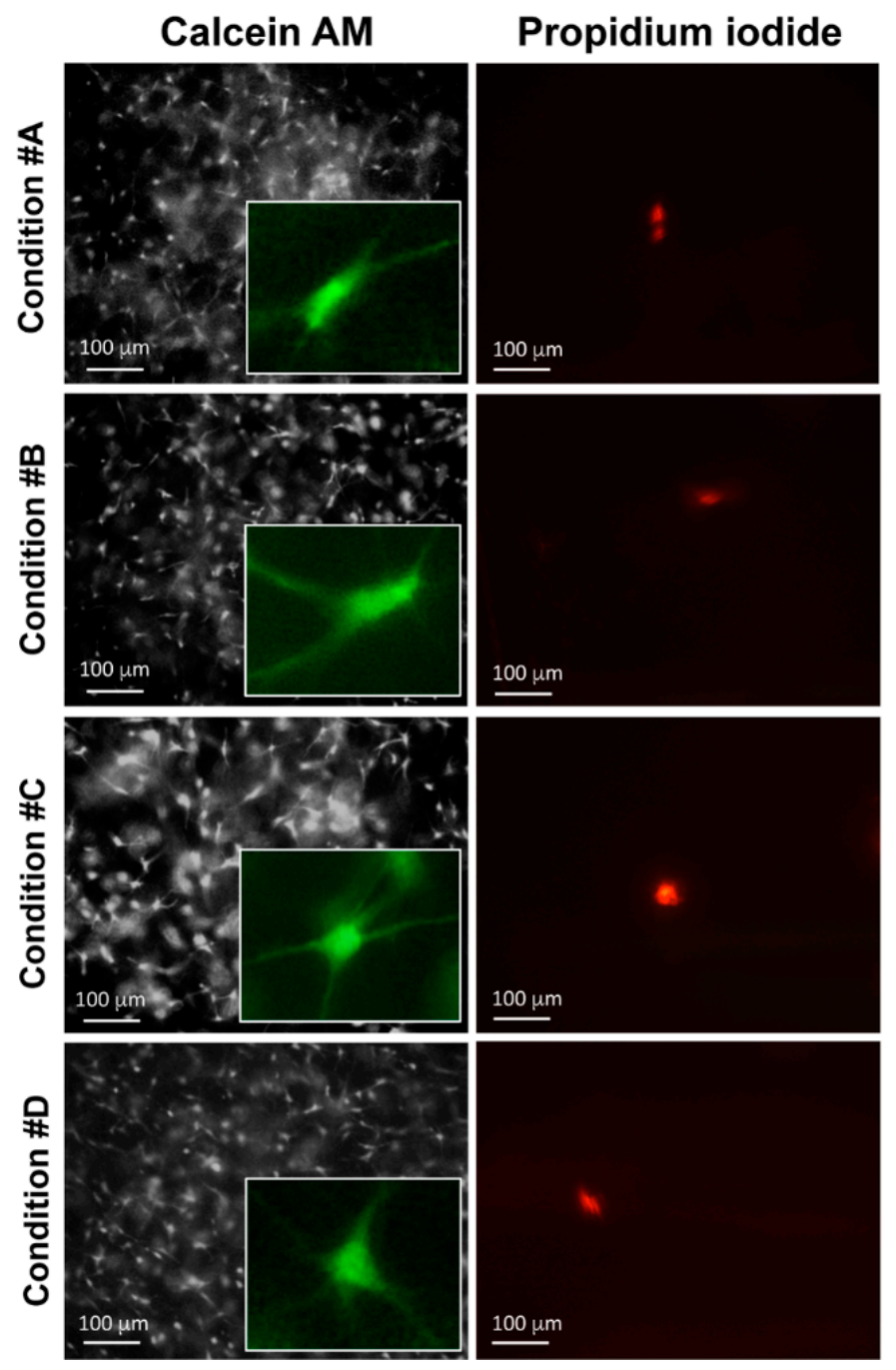

Figure 6. Live/dead fluorescence microscopy of fibroblasts embedded within collagen gels. Experimental conditions are those illustrated in Figure 1. Cell viability is assessed by calcein-AM staining and fluorescence is visible in all conditions. By contrast, only rare dead cells, stained with propidium iodide, are occasionally seen in all samples. 


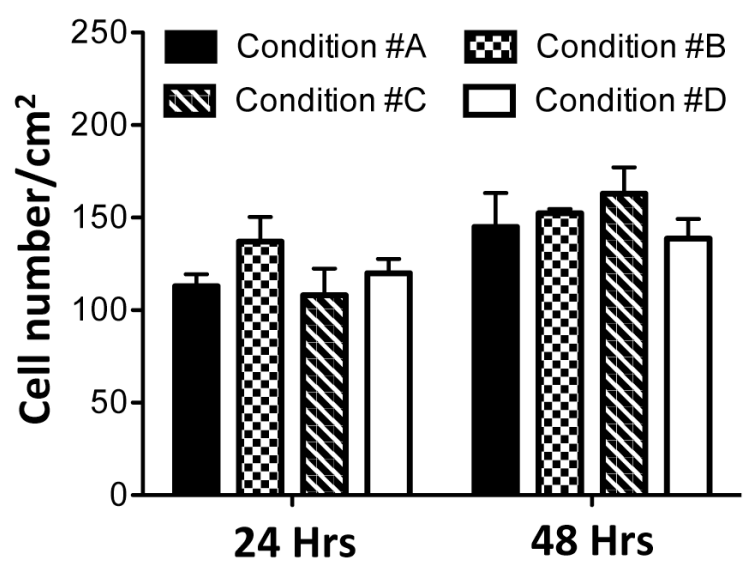

Figure 7. At 24 and $48 \mathrm{~h}$ after gel polymerization, viable cells were counted by ImageJ software. Experimental conditions are those illustrated in Figure 1. Values represent the mean of viable cell number/surface area $\left(\mathrm{cm}^{2}\right) \pm \mathrm{SD}$.

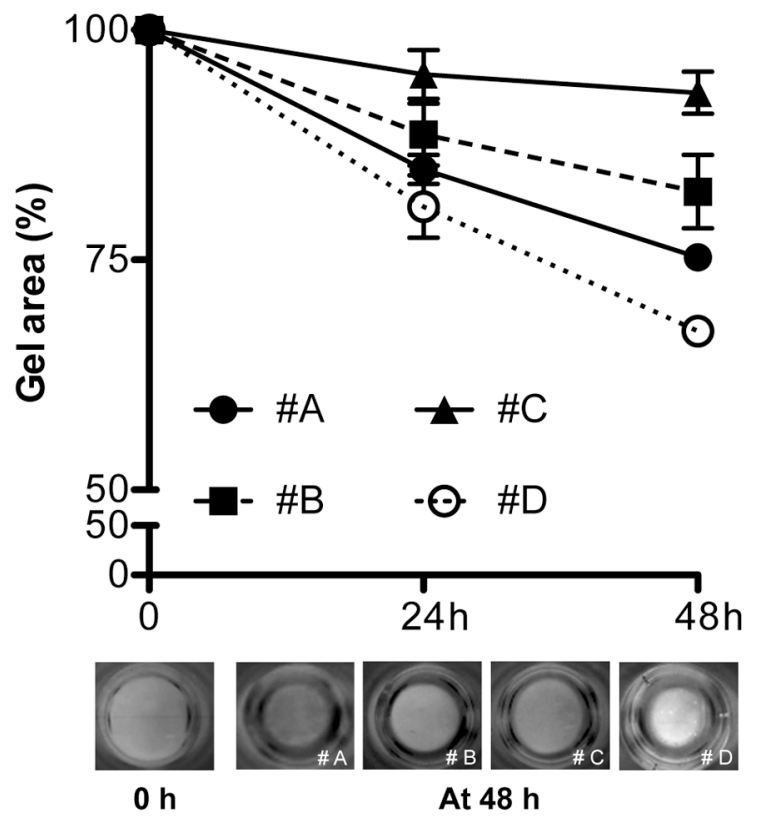

Figure 8. Collagen gel retraction after 24 and $48 \mathrm{~h}$ from cell seeding. Experimental conditions are those illustrated in Figure 1. Values represent the mean area of collagen gels \pm SEM. Representative images of collagen gels before gel retraction $(0 \mathrm{~h})$ and at $48 \mathrm{~h}$ (four experimental conditions) are also shown.

As an additional control, we prepared collagen gels in which mineralization was obtained by salt precipitation after addition of $\mathrm{CaCl}_{2}$ and $\mathrm{Na}_{4} \mathrm{P}_{2} \mathrm{O}_{7}(3 \mathrm{mM})$ at the same concentration used in in vitro smooth muscle cell models. Heavy mineralization was rapidly obtained; however, fibroblast viability appeared significantly reduced and gel retraction was negligible (Figure S2).

\section{Discussion}

To better understand the mechanisms regulating the calcification process, either in physiological and/or in pathological conditions, a number of in vitro culture systems have been already described, including a few in which mineralization is obtained by addition of alkaline phosphatase (ALP) during gel preparation $[11,12]$. 
The novelty of the present study is that collagen gels were prepared in the absence of crosslinking agents and cells were not prepared separately from the mineralized collagen gel, but added prior to polymerization, thus causing their embedding within the 3D structure. Moreover, by adding different components to the collagen solution, we have obtained gels with various structural characteristics.

To our knowledge, the most frequently used cell lines are represented by osteoblast-like cells [28] and dental pulp stem cells [29], i.e., cells that are predisposed to produce and to be in contact with a calcified extracellular matrix, or by vascular smooth muscle cells that are known to shift towards an osteoblast-like phenotype [30]. Dermal fibroblasts play a key role in soft connective tissue homeostasis, can be involved in ectopic calcification and, if cultured in two-dimensional (2D) systems for at least three weeks in the presence of pro-mineralizing factors, can produce a calcified matrix [31,32]. Nevertheless, no data are available on these cells when embedded within a calcified matrix.

In the present study, calcification, as demonstrated morphologically and by microanalysis, was enzymatically induced by exogenously added ALP in a shorter time (within $24 \mathrm{~h}$ ) [12] compared to other in vitro models (2-3 weeks), where mineralization occurred after prolonged immersion of crosslinked polymerized gels in a Ca plus $\beta$-glycerophosphate solution [33,34]. Moreover, results demonstrate that fibroblasts, although in a non-physiologic context, can adapt themselves to the mineralized environment.

In addition, collagen gel structure reflects the experimental condition and, in particular, the presence of magnesium. Besides variation in collagen concentration and in the number of loaded cells that can modify the structure/porosity of collagen gels [35,36], salts (namely divalent anions and cations) may also influence macromolecular aggregates [37], since proteins fold into specific and functional three-dimensional structures as the result of specific interactions between amino acid chemical functional groups and the surrounding solvent.

We have investigated the effect of magnesium since there is an increasing interest in this ion as a component of biomaterials used for bone replacement [38] or as a possible therapeutic agent capable of counteracting ectopic calcification [22] or as component of mineral deposits in pathological calcification [24,25]. Interestingly, in the presence of $\mathrm{MgCl}_{2}$, we have demonstrated positivity to von Kossa staining. Moreover, in our experimental condition, $\mathrm{Mg}^{2+}$ was observed in mineral deposits together with other elements. The presence of $\mathrm{Mg}$ is consistent with earlier reports where magnesium was identified in the EDX spectra of calcified valves [39] and can be incorporated, possibly with sodium and carbonate, during formation of calcium phosphate crystals [40]. Although discrimination among different apatitic deposits was beyond the scope of this study, formation of minerals with different composition, as in \#C and \#D, can better mimic the in vivo condition [41].

These findings seem in contrast with recent in vitro data excluding a physicochemical role of $\mathrm{Mg}^{2+}$ in inhibiting crystal growth or in altering calcium phosphate crystal structure and composition in vascular smooth muscle cell cultures [42]. This discrepancy can be explained by the different mineralized context (3D collagen gel vs. 2D cellular monolayer) and the method used to generate mineral deposits (enzymatic induction vs. Pi supplementation). Moreover, it has been reported that $\mathrm{Mg}^{2+}$ salts can modify collagen assembly [23]. Consistently, we have noticed a striking effect of $\mathrm{MgCl}_{2}$ on size and organization of collagen fibrils. Formation of a different porous structure could impact fibroblast's behavior and cell morphology [43]. Gel retraction, for instance, does not seem to be affected by the presence of mineral deposits per se within the 3D structure, whereas it is dependent on gel structure, being lower in the presence of a dense matrix, as in condition $\# \mathrm{C}$, and higher in the presence of large pores, as in condition $\# \mathrm{D}$, as already observed by other Authors [44].

Moreover, in \#D, although cells were less elongated compared to other experimental conditions, collagen gel was more retracted. Previous studies suggested that in fibroblasts a round shape may result from the inability of the collagen matrix to resist the force of cell contraction [45,46]. Additionally, Tamariz et al. [47] suggested that adhesive interactions of dendritic extensions were an indication of local remodeling of the collagen matrix, while the stellate/bipolar morphology was a consequence of reorganization and simplification of cell extensions during global remodeling of the whole gel. 


\section{Experimental Section}

\subsection{Preparation of Collagen Gels}

Collagen gels were prepared according to manufacturer's instructions (Gibco, Invitrogen, Milan, Italy). Briefly, a solution of type I collagen from rat tails, at the concentration of $2 \mathrm{mg} / \mathrm{mL}$, was mixed with DMEM 5X (Gibco) and $0.025 \mathrm{~N} \mathrm{NaOH}$ and allowed to be polymerized at $37^{\circ} \mathrm{C}$ for $30 \mathrm{~min}$ (Figure 1). This basal condition is referred to as condition \#A. Moreover, during gel preparation, the following components were added: $2.5 \mathrm{mM} \beta$-glycerophosphate ( $\beta$-GP, Sigma-Aldrich, St. Louis, MO, USA) and $1.25 \mathrm{mM} \mathrm{CaCl}_{2}$ (BDH AnalR, Milan, Italy) as potential sources of $\mathrm{P}$ and Ca ions necessary to form apatitic deposits (condition $\# \mathrm{~B}$ ); $\beta-\mathrm{GP}, \mathrm{CaCl}_{2}$ as in condition $\# \mathrm{~B}$, but in the presence of $1 \mathrm{U} / \mathrm{mL}$ Alkaline Phosphatase from bovine intestinal mucosa (ALP, Sigma-Aldrich, St. Louis, MO, USA), since this enzyme is required to cleave $P$ from substrates (condition \#C). Finally, to the mixture, as in condition \#C, different concentrations of $\mathrm{MgCl}_{2}$ (Riedel-DE Haen, Seelze, Germany) were added (condition \#D). As a result of a set of preliminary experiments, a working solution of $62.5 \mathrm{mM} \mathrm{MgCl}$ was used.

In addition, $400 \mu \mathrm{L}$ of each collagenous mix was quickly put in a 24-well-plate and, after polymerization, gels were gently detached before adding $500 \mu \mathrm{L}$ of DMEM. Where required, human dermal fibroblasts, at the concentration of $1.2 \times 10^{5}$ cells $/ \mathrm{mL}$, were added to collagen solutions before gel polymerization. In order to allow cells to settle in the 3D structure, all gels were allowed to stabilize for $24 \mathrm{~h}$ before morphological analyses.

\subsection{Scanning (Low Vacuum Mode) and Scanning Transmission Electron Microscopy (SEM and SEM-STEM) and Energy-Dispersive Spectroscopy (EDS)}

After dehydration and air drying, without any further treatment, samples were observed by environmental scanning electron microscopy (Nova NanoSEM 450, FEI, Hillsboro, OR, USA). Accelerating voltage was $5 \mathrm{kV}$ for morphological observations and $20 \mathrm{kV}$ for micro-analytical analyses. A gaseous analytical detector (GAD) for backscattered electrons and a large field detector (LFD) for secondary electrons were used for imaging. Microanalysis was performed using X-EDS (Quantax 200, Bruker, Berlin, Germany). Collagen fibril diameters were evaluated using the Measure and Label plugin for ImageJ. For each experimental condition, at least 30 collagen fibrils from two different areas of the gel (magnification $=\times 10,000$ ) were measured in duplicate.

For STEM observations, collagen gels were routinely fixed in $2.5 \%$ glutaraldehyde in phosphate-buffered saline (PBS), post-fixed in 1\% osmium tetroxide, dehydrated and embedded in Spurr resin. Ultrathin sections stained with uranyl acetate and lead citrate were observed by SEM-STEM (Nova NanoSEM 450-STEM).

\subsection{Histochemistry and Light Microscopy}

Collagen gels were fixed with $10 \%$ neutral buffered formalin, dehydrated and paraffin embedded. Sections, $4-\mu \mathrm{m}$ thick, were obtained with a LEICA microtome and immobilized on glass slides (Wetzlar, Germany). After deparaffinization, samples were stained with Anilin blue and observed by light microscopy (Zeiss, Jena, Germany). Von Kossa staining was applied to detected mineralization [31,32]. Briefly, sections were placed in demineralized water and exposed to $5 \%$ silver nitrate solution for $30 \mathrm{~min}$ under UV irradiation. After rinsing in demineralized water, sections were exposed to $2 \%$ sodium thiosulfate for $5 \mathrm{~min}$, rinsed again in demineralized water, dehydrated and covered with glass coverslips for microscopic analyses. Experiments were performed three times in duplicate.

\subsection{Gel Retraction and Live/Dead Assay}

Gels were prepared as described above. Human dermal fibroblasts (HDF), purchased from Thermo Fisher Scientific (Waltham, MA, USA), were routinely grown in DMEM supplemented with $10 \%$ foetal bovine serum (FBS) (Gibco-Thermo Fisher Scientific, Milan, Italy) according to standard 
procedures [48]. HDF were added to gels at a final seeding density of $1.2 \times 10^{5}$ cells $/ \mathrm{mL}$ in $2 \mathrm{mg} / \mathrm{mL}$ of collagen. In gel retraction experiments, cell-seeded collagen gels were prepared in duplicate in $35 \mathrm{~mm}$ diameter Petri dishes and evaluated at different time points $(0,6,24$ and $48 \mathrm{~h})$. After $30 \mathrm{~min}$ at $37^{\circ} \mathrm{C}$, polymerized gels were immersed in $2 \mathrm{~mL}$ of standard culture medium (DMEM supplemented with $10 \%$ FBS) and detached from the wells using a small spatula. Addition of serum is a fundamental requirement, since, in its absence, cells are not able to retract $[35,36]$. Three independent experiments were carried out in duplicate and free-floating gel retraction was assessed at the indicated time points as a percentage of the initial gel area.

Cell viability was assessed by the "live/dead staining" using calcein-AM (Sigma, St. Louis, MO, USA) and propidium iodide (Sigma, St. Louis, MO, USA). Calcein-AM is a non-fluorescent, hydrophobic compound that easily permeates intact, live cells. The hydrolysis of calcein-AM by intracellular esterases produces calcein, a hydrophilic, strongly fluorescent compound that is well-retained in the cell cytoplasm.

Propidium iodide (PI) is impermeable to cells with an intact plasma membrane, hence when the cell integrity becomes compromised, it gains access to the nucleus, where it complexes with DNA, rendering the nucleus highly fluorescent [27].

Collagen gels were rinsed in PBS, incubated for $10 \mathrm{~min}$ at room temperature with $2 \mathrm{~mL}$ of calcein-AM (5 $\mu \mathrm{M}$ in PBS) and of propidium iodide (1 $\mathrm{mg} / \mathrm{mL}$ in PBS). Cells were washed twice with PBS and observed by fluorescence microscopy at 24 and $48 \mathrm{~h}$ after seeding.

\subsection{Statistical Analysis}

Data were expressed as mean values \pm SD/SEM of all measurements and compared by ANOVA test with significance at $p<0.05$. Statistical data were obtained using GraphPad software, version 5.0 (San Diego, CA, USA).

\section{Conclusions}

In conclusion, this study demonstrates that, in a short time, an enzymatically mineralized collagen gel can be prepared in which mineral deposits and viable cells are homogeneously distributed. The effect of $\mathrm{MgCl}_{2}$ on collagen fibril assembly and organization highlights the importance of this ion in modifying matrix structural characteristics. The development of structurally different 3D mineralized collagen matrices, together with the use of fibroblasts, as prototype of sot connective tissue mesenchymal cells, may pave new ways for the study of ectopic calcification.

Supplementary Materials: The following are available online at www.mdpi.com/1996-1944/9/6/477/s1.

Acknowledgments: Work was supported by a grant from FCRM "Ectocal". The authors acknowledge the "Fondazione Cassa di Risparmio di Modena" for funding the Scanning and Transmission Electron Microscopy system at the Centro Interdipartimentale Grandi Strumenti (CIGS) of the University of Modena and Reggio Emilia.

Author Contributions: Federica Boraldi and Daniela Quaglino designed the experiments; Angelica Bartolomeo and Giulia Annovi performed the experiments; Federica Boraldi and Roman Debret analyzed the data; Federica Boraldi and Daniela Quaglino wrote the paper.

Conflicts of Interest: The authors declare no conflict of interest.

\section{References}

1. Perez, R.A.; Won, J.E.; Knowles, J.C.; Kim, H.W. Naturally and synthetic Smart Composite Biomaterials for Tissue Regeneration. Adv. Drug Deliv. Rev. 2013, 65, 471-496. [CrossRef] [PubMed]

2. Holzwarth, J.M.; Ma, P.X. Biomimetic Nanofibrous Scaffolds for Bone Tissue Engineering. Biomaterials 2011, 32, 9622-9629. [CrossRef] [PubMed]

3. Gleeson, J.P.; Plunkett, N.A.; O’Brien, F.J. Addition of hydroxyapatite improves stiffness, interconnectivity and osteogenic potential of a highly porous collagen-based scaffold for bone tissue regeneration. Eur. Cells Mater. 2010, 20, 218-230. 
4. Zhou, Y.; Yao, H.; Wang, J.; Wang, D.; Liu, Q.; Li, Z. Greener synthesis of electrospun collagen/hydroxyapatite composite fibers with an excellent microstructure for bone tissue engineering. Int. J. Nanomed. 2015, 10, 3203-3215.

5. Wang, Y.; Azaïs, T.; Robin, M.; Vallée, A.; Catania, C.; Legriel, P.; Pehau-Arnaudet, G.; Babonneau, V.; Giraud-Guille, M.M.; Nassif, N. The predominant role of collagen in the nucleation, growth, structure and orientation of bone apatite. Nat. Mater. 2012, 11, 724-733. [CrossRef] [PubMed]

6. George, A.; Veis, A. Phosphorylated proteins and control over apatite nucleation, crystal growth, and inhibition. Chem. Rev. 2008, 108, 4670-4693. [CrossRef] [PubMed]

7. Roberts, J.E.; Bonar, L.C.; Griffin, R.G.; Glimcher, M.J. Characterization of very young mineral phases of bone by solid state 31phosphorus magic angle sample spinning nuclear magnetic resonance and X-ray diffraction. Calcif. Tissue Int. 1992, 50, 42-48. [CrossRef] [PubMed]

8. Olszta, J.M.; Chenga, X.; Jeea, S.S.; Kumara, R.; Kima, Y.Y.; Kaufmane, M.J.; Douglasa, E.P.; Laurie, B. Bone structure and formation: A new perspective. Mater. Sci. Eng. R 2007, 58,77-116. [CrossRef]

9. Silver, F.H.; Landis, W.J. Deposition of apatite in mineralizing vertebrate extracellular matrices: A model of possible nucleation sites on type I collagen. Connect. Tissue Res. 2001, 52, 242-254. [CrossRef] [PubMed]

10. Deshpande, A.S.; Fang, P.A.; Zhang, X.; Jayaraman, T.; Sfeir, C.; Beniash, E. Primary structure and phosphorylation of dentin matrix protein 1 (DMP1) and dentin phosphophoryn (DPP) uniquely determine their role in biomineralization. Biomacromolecules 2011, 12, 2933-2945. [CrossRef] [PubMed]

11. Yamauchi, K.; Goda, T.; Takeuchi, N.; Einaga, H.; Tanabe, T. Preparation of collagen/calcium phosphate multilayer sheet using enzymatic mineralization. Biomaterials 2004, 25, 5481-5489. [CrossRef] [PubMed]

12. Douglas, T.E.; Messersmith, P.B.; Chasan, S.; Mikos, A.G.; de Mulder, E.L.; Dickson, G.; Schaubroeck, D.; Balcaen, L.; Vanhaecke, F.; Dubruel, P.; et al. Enzymatic mineralization of hydrogels for bone tissue engineering by incorporation of alkaline phosphatase. Macromol. Biosci. 2012, 12, 1077-1089. [CrossRef] [PubMed]

13. Uchihashi, K.; Aoki, S.; Matsunobu, A.; Toda, S. Osteoblast migration into type I collagen gel and differentiation to osteocyte-like cells within a self-produced mineralized matrix: A novel system for analyzing differentiation from osteoblast to osteocyte. Bone 2013, 52, 102-110. [CrossRef] [PubMed]

14. Ghezzi, C.E.; Marelli, B.; Donelli, I.; Alessandrino, A.; Freddi, G.; Nazhat, S.N. Multilayered dense collagen-silk fibroin hybrid: A platform for mesenchymal stem cell differentiation towards chondrogenic and osteogenic lineages. J. Tissue Eng. Regen. Med. 2015, 9. [CrossRef] [PubMed]

15. Liu, G.; Pastakia, M.; Fenn, M.B.; Kishore, V. Saos-2 Cell Mediated Mineralization on Collagen Gels: Effect of Densification and Bioglass Incorporation. J. Biomed. Mater. Res. A 2016, 104, 1121-1134. [CrossRef] [PubMed]

16. Liu, Y.; Williams, D.J. Incorporation of hydroxyapatite sol into collagen gel to regulate the contraction mediated by human bone marrow-derived stromal cells. IEEE Trans. Nanobiosci. 2010, 9, 1-11.

17. Ronchetti, I.; Boraldi, F.; Annovi, G.; Cianciulli, P.; Quaglino, D. Fibroblast involvement in soft connective tissue calcification. Front. Genet. 2013, 4. [CrossRef] [PubMed]

18. Yang, Y.L.; Motte, S.; Kaufman, L.J. Pore size variable type I collagen gels and their interaction with glioma cells. Biomaterials 2010, 31, 5678-5688. [CrossRef] [PubMed]

19. Sapudom, J.; Rubner, S.; Martin, S.; Kurth, T.; Riedel, S.; Mierke, C.T.; Pompe, T. The phenotype of cancer cell invasion controlled by fibril diameter and pore size of 3D collagen networks. Biomaterials 2015, 52, 367-375. [CrossRef] [PubMed]

20. Dong, B.; Arnoult, O.; Smith, M.E.; Wnek, G.E. Electrospinning of collagen nanofiber scaffolds from benign solvents. Macromol. Rapid Commun. 2009, 30, 539-542. [CrossRef] [PubMed]

21. Roeder, B.A.; Kokini, K.; Voytik-Harbin, S.L. Fibril microstructure affects strain transmission within collagen extracellular matrices. J. Biomech. Eng. 2009, 131. [CrossRef] [PubMed]

22. LaRusso, J.; Li, Q.; Jiang, Q.; Uitto, J. Elevated dietary magnesium prevents connective tissue mineralization in a mouse model of pseudoxanthoma elasticum (Abcc6(-/-)). J. Investig. Dermatol. 2009, 129, 1388-1394. [CrossRef] [PubMed]

23. Wang, L.; Guo, Y.; Li, P.; Song, Y. Anion-specific effects on the assembly of collagen layers mediated by magnesium ion on mica surface. J. Phys. Chem. B 2014, 118, 511-518. [CrossRef] [PubMed]

24. Eidelman, N.; Boyde, A.; Bushby, A.J.; Howell, P.G.; Sun, J.; Newbury, D.E.; Miller, F.W.; Robey, P.G.; Rider, L.G. Microstructure and mineral composition of dystrophic calcification associated with the idiopathic inflammatory myopathies. Arthritis Res. Ther. 2009, 11. [CrossRef] [PubMed] 
25. Delogne, C.; Lawford, P.V.; Habesch, S.M.; Carolan, V.A. Characterization of the calcification of cardiac valve bioprostheses by environmental scanning electron microscopy and vibrational spectroscopy. J. Microsc. 2007, 228, 62-77. [CrossRef] [PubMed]

26. Yamanishi, H.; Sato, V. The removal of non-collagen components from newborn calf dermis with magnesium chloride solution. J. Biochem. 1976, 79, 131-144. [PubMed]

27. Brana, C.; Benham, C.; Sundstrom, L. A method for characterising cell death in vitro by combining propidium iodide staining with immunohistochemistry. Brain Res. Protoc. 2002, 10, 109-114. [CrossRef]

28. Addison, W.N.; Nelea, V.; Chicatun, F.; Chien, Y.C.; Tran-Khanh, N.; Buschmann, M.D.; Nazhat, S.N.; Kaartinen, M.T.; Vali, H.; Tecklenburg, M.M.; et al. Extracellular matrix mineralization in murine MC3T3-E1 osteoblast cultures: An ultrastructural, compositional and comparative analysis with mouse bone. Bone 2015, 71, 244-256. [CrossRef] [PubMed]

29. Widbiller, M.; Lindner, S.R.; Buchalla, W.; Eidt, A.; Hiller, K.A.; Schmalz, G.; Galler, K.M. Three-dimensional culture of dental pulp stem cells in direct contact to tricalcium silicate cements. Clin. Oral Investig. 2016, 20, 237-246. [CrossRef] [PubMed]

30. Steitz, S.A.; Speer, M.Y.; Curinga, G.; Yang, H.Y.; Haynes, P.; Aebersold, R.; Schinke, T.; Karsenty, G.; Giachelli, C.M. Smooth muscle cell phenotypic transition associated with calcification: Upregulation of Cbfa1 and downregulation of smooth muscle lineage markers. Circ. Res. 2001, 89, 1147-1154. [CrossRef] [PubMed]

31. Boraldi, F.; Annovi, G.; Vermeer, C.; Schurgers, L.J.; Trenti, T.; Tiozzo, R.; Guerra, D.; Quaglino, D. Matrix gla protein and alkaline phosphatase are differently modulated in human dermal fibroblasts from PXE patients and controls. J. Investig. Dermatol. 2013, 133, 946-954. [CrossRef] [PubMed]

32. Boraldi, F.; Annovi, G.; Bartolomeo, A.; Quaglino, D. Fibroblasts from patients affected by Pseudoxanthoma elasticum exhibit an altered PPi metabolism and are more responsive to pro-calcifying stimuli. J. Dermatol. Sci. 2014, 74, 72-80. [CrossRef] [PubMed]

33. Banks, E.; Nakajima, S.; Shapiro, L.C.; Tilevitz, O. Fibrous apatite on modified collagen. Science 1997, 198, 1164-1166. [CrossRef]

34. Doi, Y.; Horiguchi, T.; Moriwaki, Y.; Kitago, H.; Kajimoto, T.; Iwayama, Y. Formation of apatite-collagen complexes. J. Biomed. Mater. Res. 1996, 31, 43-49. [CrossRef]

35. Grinnell, F. Fibroblast-collagen-matrix contraction: Growth-factor signalling and mechanical loading. Trends Cell Biol. 2000, 10, 362-365. [CrossRef]

36. Freyman, T.M.; Yannas, I.V.; Yokoo, R.; Gibson, L.J. Fibroblast contractile force is independent of the stiffness which resists the contraction. Exp. Cell Res. 2002, 272, 153-162. [CrossRef] [PubMed]

37. Kunz, W.; Henle, J.; Ninham, B.W. Zur Lehre von der Wirkung der Salze' (about the science of the effect of salts): Franz Hofmeister's historical papers. Curr. Opin. Colloid Interface Sci. 2004, 9, 19-37. [CrossRef]

38. Farraro, K.F.; Kim, K.E.; Woo, S.L.; Flowers, J.R.; McCullough, M.B. Revolutionizing orthopaedic biomaterials: The potential of biodegradable and bioresorbable magnesium-based materials for functional tissue engineering. J. Biomech. 2014, 47, 1979-1986. [CrossRef] [PubMed]

39. Lee, Y.S. Morphogenesis of calcification in porcine bioprosthesis: Insight from high resolution electron microscopic investigation at molecular and atomic resolution. J. Electron. Microsc. 1993, 42, 156-165.

40. Huang-Lee, L.H.H.; Cheung, D.T.; Nimni, M.E. Biochemical changes and cytotoxicity associated with the degradation of polymeric glutaraldehyde derived cross-links. J. Biomed. Mater. Res. 1990, 24, 1185-1201. [CrossRef] [PubMed]

41. Mavrilasa, D.; Apostolakia, A.; Kapolosb, J.; Koutsoukosb, P.G.; Melachrinouc, M.; Zolotac, V.; Dougenisd, D. Development of bioprosthetic heart valve calcification in vitro and in animal models: Morphology and composition. J. Cryst. Growth 1999, 4, 554-562. [CrossRef]

42. Louvet, L.; Bazin, D.; Büchel, J.; Steppan, S.; Passlick-Deetjen, J.; Massy, Z.A. Characterisation of calcium phosphate crystals on calcified human aortic vascular smooth muscle cells and potential role of magnesium. PLoS ONE 2015, 10. [CrossRef] [PubMed]

43. Gorgieva, S.; Strancar, J.; Kokol, V. Evaluation of surface/interface-related physicochemical and microstructural properties of gelatin 3D scaffolds, and their influence on fibroblast growth and morphology. J. Biomed. Mater. Res. Part A 2014, 102, 3986-3997. [CrossRef] [PubMed]

44. Mendoza, M.; Wittel, F.K.; Herrmann, H.J. Simulation of flow of mixtures through anisotropic porous media using a lattice Boltzmann model. Eur. Phys. J. E Soft Matter. 2010, 32, 339-348. [CrossRef] [PubMed] 
45. Menezes, G.C.; Miron-Mendoza, M.; Ho, C.H.; Jiang, H.; Grinnell, F. Oncogenic Ras-transformed human fibroblasts exhibit differential changes in contraction and migration in 3D collagen matrices. Exp. Cell Res. 2008, 314, 3081-3091. [CrossRef] [PubMed]

46. Grinnell, F.; Ho, C.H. The effect of growth factor environment on fibroblast morphological response to substrate stiffness. Biomaterials 2013, 34, 965-974. [CrossRef] [PubMed]

47. Tamariz, E.; Grinnell, F. Modulation of fibroblast morphology and adhesion during collagen matrix remodelling. Mol. Biol. Cell 2002, 13, 3915-3929. [CrossRef] [PubMed]

48. Quaglino, D.; Boraldi, F.; Barbieri, D.; Croce, A.; Tiozzo, R.; Pasquali Ronchetti, I. Abnormal phenotype of in vitro dermal fibroblasts from patients with Pseudoxanthoma elasticum (PXE). Biochim. Biophys. Acta 2000, 1501, 51-62. [CrossRef]

(C) 2016 by the authors; licensee MDPI, Basel, Switzerland. This article is an open access article distributed under the terms and conditions of the Creative Commons Attribution (CC-BY) license (http://creativecommons.org/licenses/by/4.0/). 